\title{
Modular Total Syntheses of the Alkaloids Discoipyrroles A and B, Potent Inhibitors of the DDR2 Signalling Pathway
}

Yiwen Zhang, Martin G. Banwell,* Paul D. Carr and Anthony C. Willis

Research School of Chemistry, Institute of Advanced Studies

The Australian National University, Canberra, ACT 2601, Australia

\begin{abstract}
The title natural product 1 has been synthesised by treating the 1,2,3,5tetra-substituted pyrrole $\mathbf{2 3}$ with oxoperoxymolybdenum(pyridine)(hexamethylphosphoric triamide) (MoOPH). Compound 23 was itself prepared in seven steps from parent pyrrole using Ullmann-Goldberg and Suzuki-Miyaura cross coupling, VilsmeierHaack formylation, electrophilic bromination, and Witting olefination reactions as key steps. Related chemistry has been used to prepare discoipyrrole B (2).
\end{abstract}

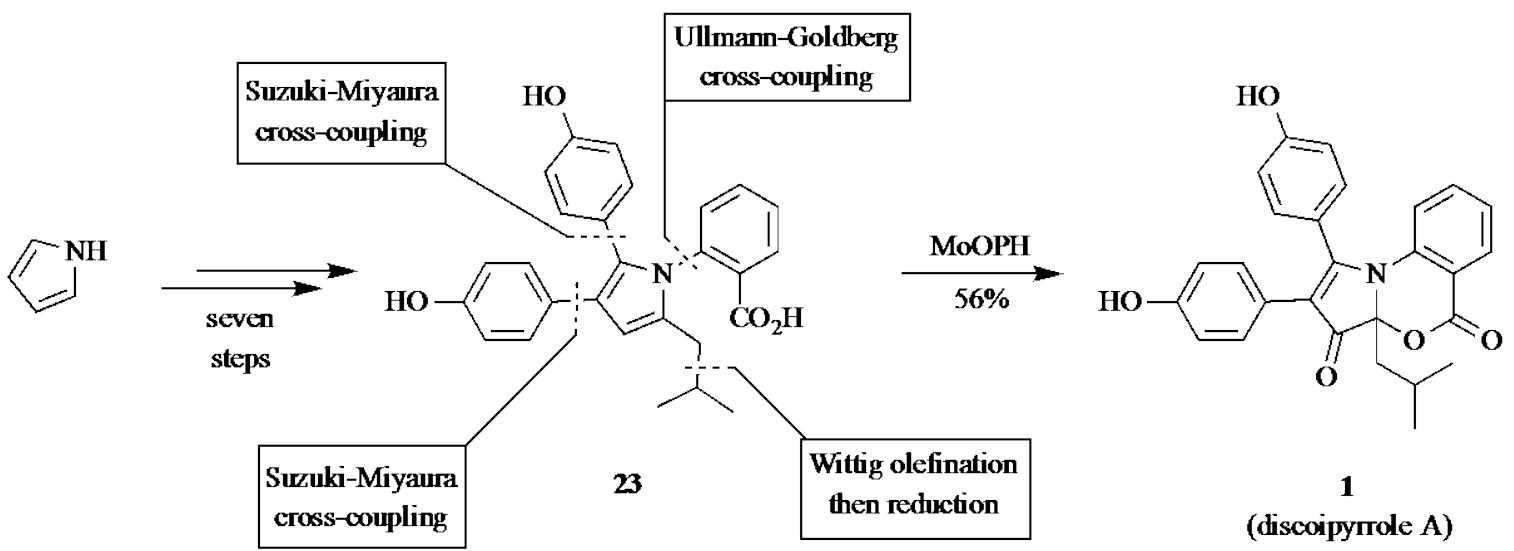

In 2013 MacMillan and co-workers reported $^{1}$ the isolation, using a functional signature-based ontology (FUSION) map approach, ${ }^{1,2}$ of four new alkaloids from the marine-derived Bacillus hunanensis strain SNA-048. Using a range of relatively conventional spectroscopic techniques they assigned structures 1-4 (Figure 1) to these compounds and named them discoipyrroles A-D, respectively. ${ }^{1}$ Each was isolated as the racemate and the structure of the first ( $v i z .1$ ) was confirmed by single-crystal $\mathrm{X}^{-}$ ray analysis of the bis-p-bromobenzoate derivate of the $(-)$-enantiomer obtained using chiral-phase HPLC techniques.

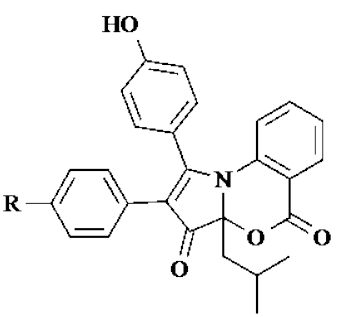

$1(\mathrm{R}=\mathrm{OH}$, discoipyrrole $\mathrm{A})$ $2(\mathrm{R}=\mathrm{H}$, discoipyrrole $\mathrm{B})$

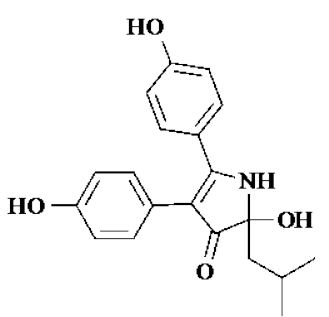

3 (discoipyrrole C)

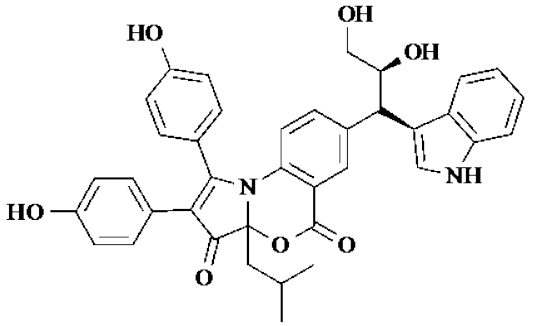

4 (discoipyrrole D)

Figure 1: Discoipyrroles A-D 
Discoipyrroles 1,2 and 4 are the first examples of natural products that embody a $3 H$-benzo $[d]$ pyrrole $[1,3]$ oxazine-3,5-dione core. All four compounds proved to be particularly strong inhibitors of the discoidin domain receptor 2 or DDR2-dependent migration of BR5 fibroblasts. ${ }^{1}$ They also showed selective cytotoxicity towards DDR2 mutant lung cancer cell lines $\left(\mathrm{IC}_{50}\right.$ 120-400 nM). As such, these natural products and their analogues could provide important new tools for interrogating the DDR2 signaling pathway, one that has been implicated in various cancers, ${ }^{3}$ fibroblast migration and proliferation ${ }^{4}$ as well as obstructive diseases of blood vessels. ${ }^{5}$

The biogenesis of the racemic discoipyrroles is believed to be nonenzymic in nature and involves, in the case of compound 1 for example, oxidative coupling of 2-hydroxy-1-(p-hydroxyphenyl)-5-methylhexan-3one and $p$-hydroxybenzaldehyde with the resulting 1,3,4-trione engaging in successive inter- then intra-molecular condensation reactions with the amine and carboxylic acid residues, respectively, of anthranilic acid. ${ }^{1}$ Various feeding experiments have served to support such proposals and by mixing the three reaction partners just mentioned in dimethyl sulfoxide containing $1 \%$ trifluoroacetic acid at $50{ }^{\circ} \mathrm{C}$ then modest amounts of discoipyrrole A were obtained as an admixture with a number of side-products. ${ }^{1}$ A variation on this theme has been employed by May and co-workers in the total synthesis of discoipyrrole D (4). ${ }^{6}$

The fascinating origins, structures and biological activities of the discoipyrroles together with the potential for "tuned" analogues to serve as molecular probes of the DDR2 cellular signaling process prompted us to investigate means for establishing completely modular (and rational) syntheses of such systems. Herein we report the assembly, via successive cross-coupling and alkenylation chemistries, of compounds of the general form 5 (Figure 2) and their successful oxidative cyclisation to generate the corresponding $3 H$-benzo $[d]$ pyrrole $[1,3]$ oxazine-3, 5-diones 6 including discoipyrroles A and $\mathrm{B}$ ( 1 and 2 , respectively). ${ }^{7}$

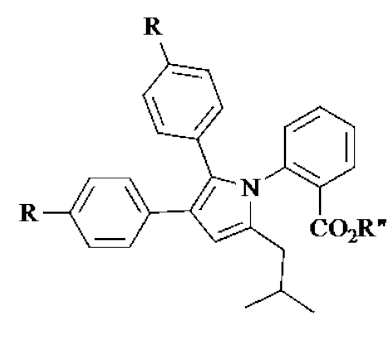

5

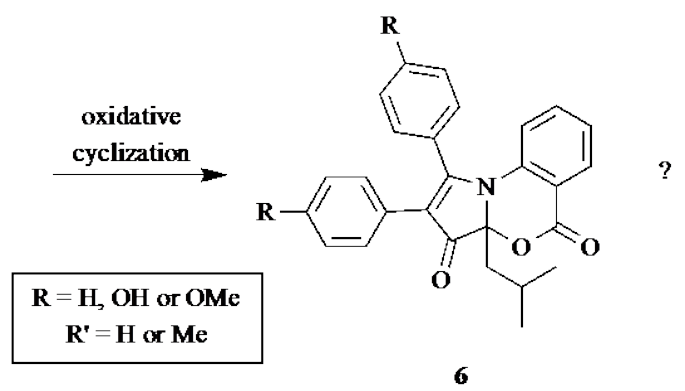

Figure 2: The proposed oxidative cyclisation of a 1,2,3,5-tetrasubstituted pyrrole 5 to the afford $3 H$-benzo $[d]$ pyrrole $[1,3]$ oxazine-3,5-dione framework 6 of discoipyrroles A, B and D. 
The first approach used in attempts to prepare pyrroles of the general form 5 is shown in Scheme 1 and started with the two-fold electrophilic bromination of readily available $1 H$ pyrrole-2-carboxaldehyde (7) using $N$-bromosuccinimide (NBS) and so affording the previously reported ${ }^{8}$ dibromo-derivative 8 in 99\% yield. Suzuki-Miyaura cross coupling of this last compound with 5 molar equivalents of commercially available $p$ methoxyphenylboronic acid (9) provided the previously unreported diarylated pyrrole 10 in $75 \%$ yield. ${ }^{9}$ On reaction with isopropylmagnesium bromide in THF aldehyde 10 afforded the expected but unstable $2^{\circ}$-alcohol that was treated, in situ, with lithium aluminum hydride $\left(\mathrm{LiAlH}_{4}\right)$ and thereby effecting reductive cleavage of the hydroxy group to produce the iso-butyl-substituted pyrrole 11 in $96 \%$ yield (from 10). ${ }^{10}$
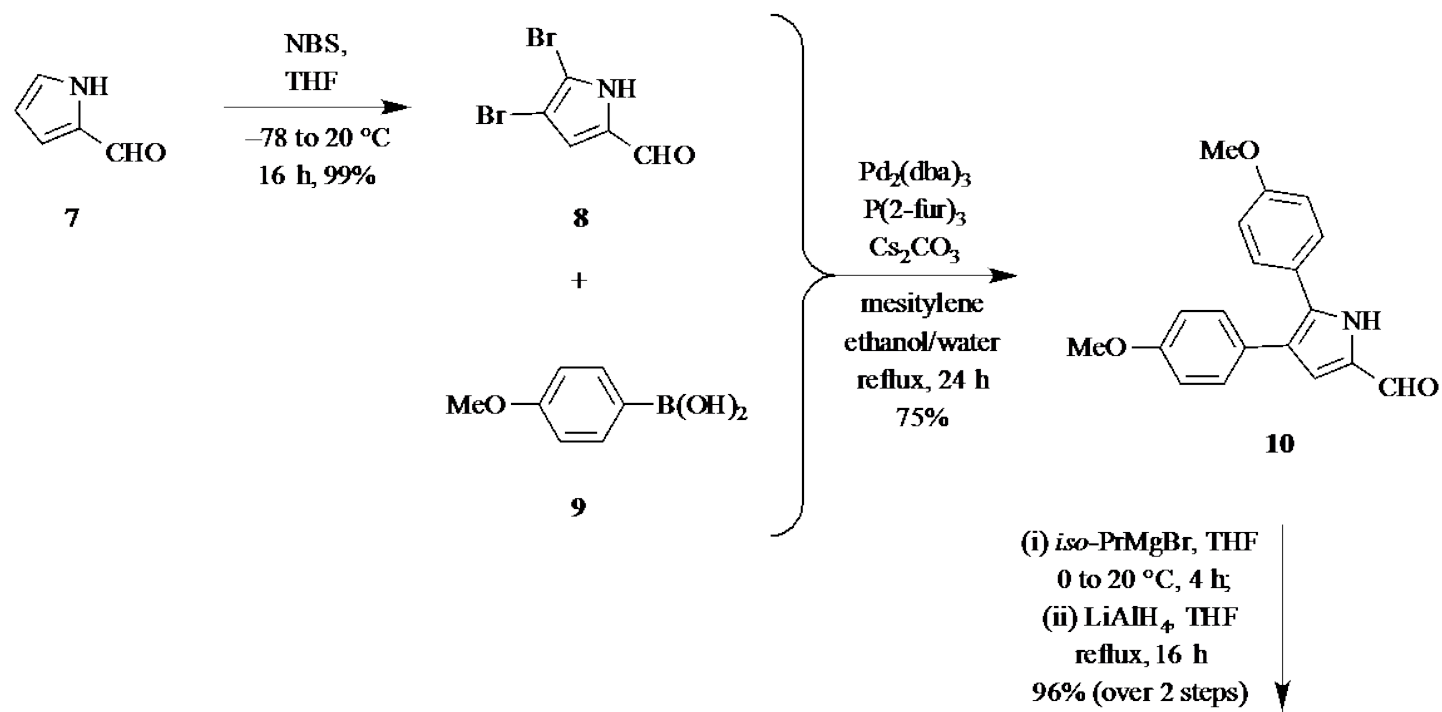

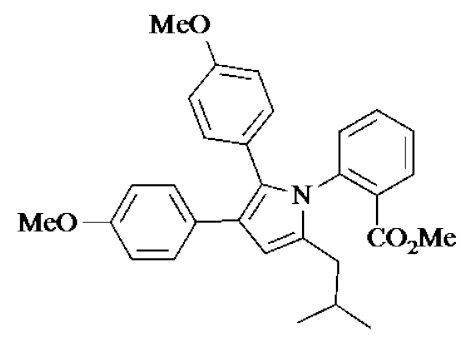

12

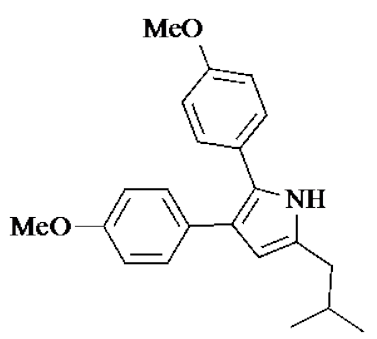

11

Scheme 1: Attempted synthesis of the 1,2,3,5-tetrasubstituted pyrrole 12 via $\mathrm{N}$-arylation of precursor $\mathbf{1 1}$

Unfortunately, all attempts to effect the $N$-arylation of compound $\mathbf{1 1}$ using various methyl $o$-halobenzoates under a range of different conditions, including modern variants of the Ullmann-Goldberg reaction, ${ }^{11}$ failed. Such outcomes are attributed to the sterically congested environment about the nitrogen of pyrrole $\mathbf{1 1}$ resulting from the presence of the flanking aryl and iso-butyl groups at C2 and C5, respectively. 
In an effort to address the difficulties described immediately above a re-ordering of the cross coupling and alkylation processes was investigated as shown in Scheme 2. Thus, pyrrole (13) was crossed coupled with methyl o-iodobenzoate (14) using conditions very similar to those reported by Buchwald ${ }^{11 a, b}$ and thereby affording the anticipated and previously reported product $\mathbf{1 5}^{12}$ (99\%). Subjection of the latter compound to a standard Vilsmeier-Haack formylation reaction using $N, N$-dimethylformamide (DMF) and $\mathrm{POCl}_{3}$ afforded aldehyde $\mathbf{1 6}^{13}$ (59\%) that could be dibrominated with NBS under the same conditions as described earlier and so delivering the dihalogenated product 17 in $99 \%$ yield.

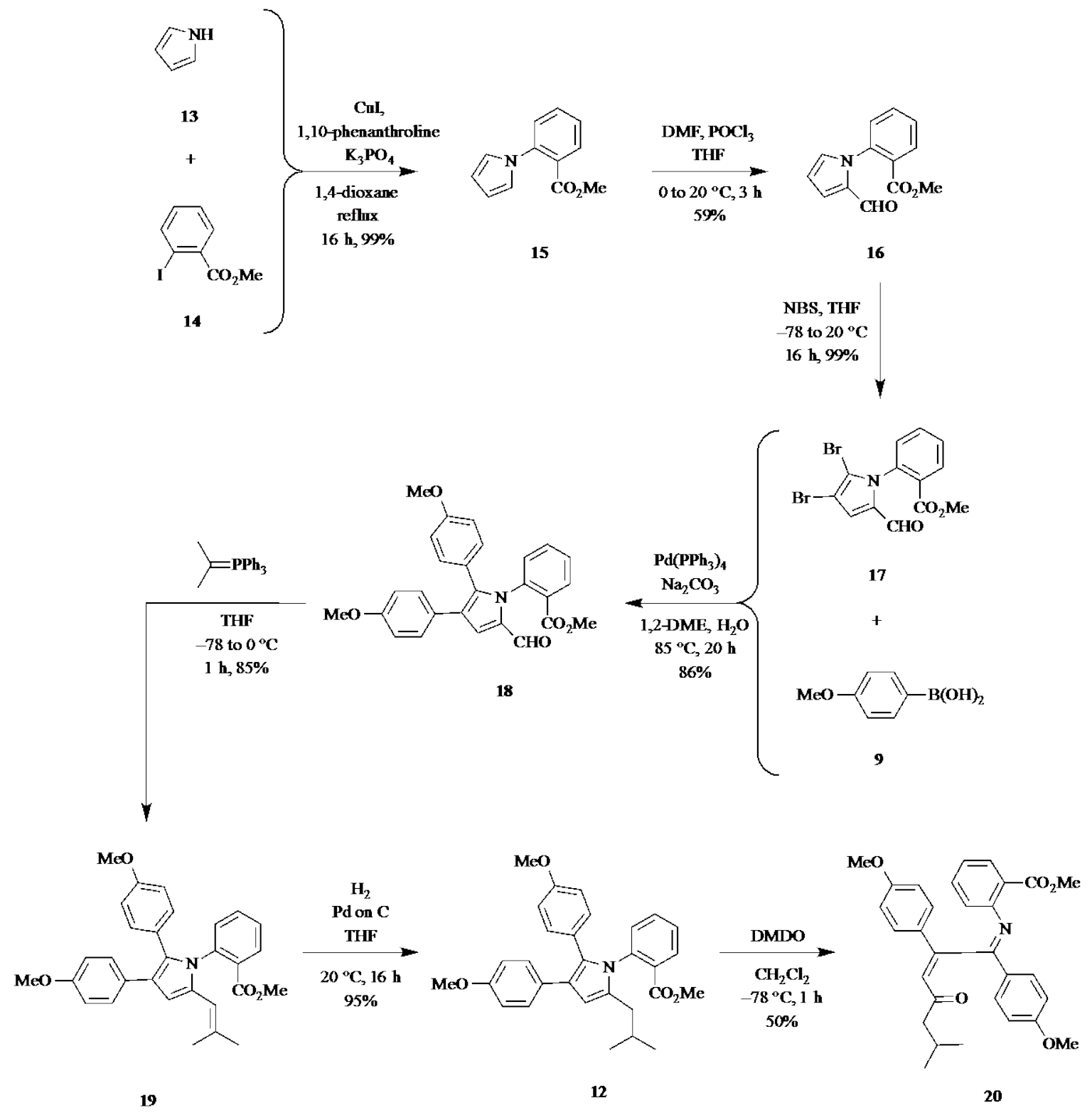

Scheme 2: Synthesis of the 1,2,3,5-tetrasubstituted pyrrole 12 and an attempt to effect its oxidative cyclisation

Two-fold Suzuki-Miyaura cross coupling of this last compound with boronic acid $\mathbf{9}$ then gave the 1,2,3-triarylated pyrrole-2- carboxaldehyde 18 (86\%) that was itself subject to a Wittig olefination reaction using the ylid obtained by treating iso- 
propyltriphenylphosphonium iodide with potassium tert-butoxide. The iso-butene 19 (85\%) so-formed was subjected to hydrogenation at atmospheric pressures using palladium on carbon as catalyst and the targeted C5-iso-buylated and triaryl-substituted pyrrole 12 thereby obtained in 95\% yield.

On the basis that the pyrrole ester $\mathbf{1 2}$ might undergo an oxidative cyclisation reaction of the type shown in Figure 2 it was treated with a freshly prepared solution of dimethyldioxirane (DMDO) in acetone at $-78{ }^{\circ} \mathrm{C}$. A rather complex mixture of products was formed and after chromatography the oxidatively ring-cleaved product $\mathbf{2 0}$ was obtained in $50 \%$ yield. The structure of this rather unstable compound was secured by single-crystal X-ray analysis (details provided in the SI). This conversion is believed to involve initial epoxidation of the $\Delta^{4,5}$-double bond within substrate 12 with the resulting oxirane then fragmenting, via successive $\mathrm{C}-\mathrm{O}$ and $\mathrm{C}-\mathrm{N}$ bond cleavages, to give the observed product.

Various studies have been conducted on the oxidation of the indole C2-C3 double bond using $\mathrm{MoO}_{5}$-based systems and the primary intermediates so-generated have been trapped by a range of external nucleophiles such as methanol so as to generate, for example, 2-methoxyindolin-3-ones. ${ }^{14}$ No analogous studies appear to have been carried out with pyrroles or with any systems incorporated internal nucleophiles. Since a carboxylic acid residue was required as an internal nucleophile in the present instance, the ester 12 was saponified (Scheme 3) using potassium hydroxide and after work up with aqueous $\mathrm{HCl}$ the corresponding carboxylic acid $\mathbf{2 1}$ was obtained in 99\% yield.

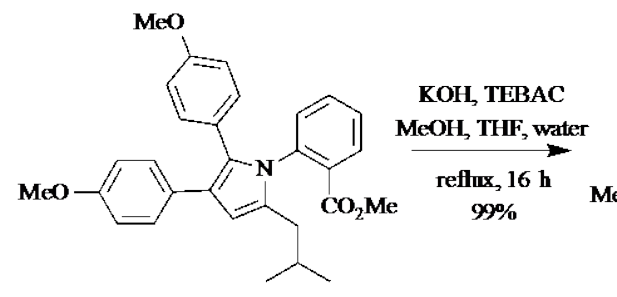

12

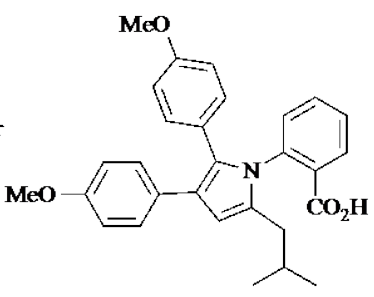

21

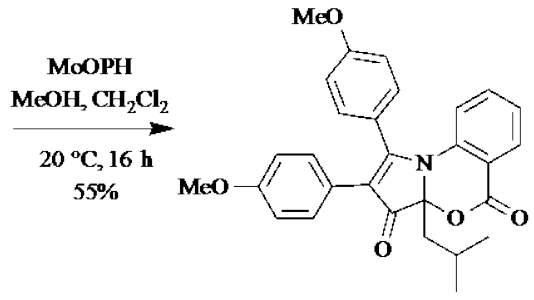

22

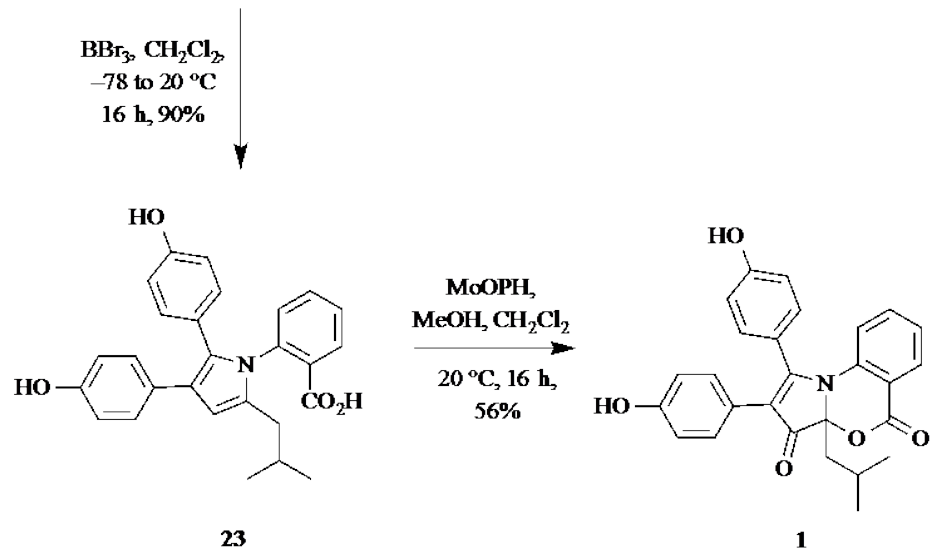

Scheme 3: Successful oxidative cyclisation reactions leading to discoipyrrole A (1) and its bis-O-methyl ether 22.

Gratifyingly, when a solution of compound 21 in dichloromethane/methanol was treated, at $20{ }^{\circ} \mathrm{C}$ for $16 \mathrm{~h}$, with freshly prepared oxoperoxymolybdenum(pyridine)(hexamethyl- 
phosphoric triamide) $(\mathrm{MoOPH})^{15}$ then the desired $3 H$-benzo $[d]$ pyrrole $[1,3]$ oxazine3,5 -dione 22 was obtained in $55 \%$ yield after chromatographic purification. All the spectroscopic data acquired on this oxidative cyclisation product (see SI for details) were in complete accord with the assigned structure. Most particularly, the ${ }^{13} \mathrm{C}$ NMR spectrum displayed the expected twenty-five resonances, including ones at $\delta_{c} 194.3$ and 168. 6 that are assigned to the ketone and lactone carbonyl carbons, respectively. Furthermore, the infrared spectrum of compound 22 displayed carbonyl stretching bands at 1740 and $1700 \mathrm{~cm}^{-1}$ while the electrospray ionization mass spectrum revealed molecular associated ions at $m / z 470\left[(\mathrm{M}+\mathrm{H})^{+}\right]$and $492\left[(\mathrm{M}+\mathrm{Na})^{+}\right]$.

A second substrate, bis-phenol 23, used to examine the scope of the oxidative cyclisation process was obtained in $90 \%$ yield through the boron tribromide-mediated demethylation of compound 21. On treatment with MoOPH in dichloromethane compound 23 was converted into discoipyrrole $(1)^{1}(56 \%)$, the derived spectral data for which proved an excellent match with those reported for the natural product (see SI for comparisons of the ${ }^{1} \mathrm{H}$ and ${ }^{13} \mathrm{C}$ NMR spectra data sets).

The utility of the modular syntheses of $3 H$ benzo $[d]$ pyrrole $[1,3]$ oxazine3,5-diones reported here is enhanced by the observation that regioselective Suzuki-Miyaura arylation reactions of the dibromopyrrole 17 are possible (Scheme 4). ${ }^{8 a, 16}$ So, for example, when this compound was cross coupled with 1.2 molar equivalents of boronic acid 9 then the diarylated pyrrole 24 (not isolated) was obtained and immediately

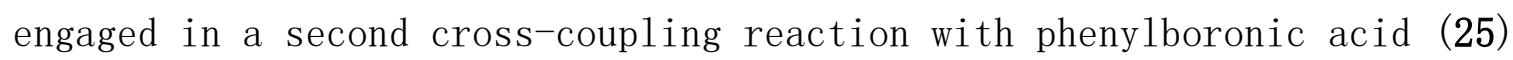
to give the triarylated pyrrole 26 in $77 \%$ yield. 

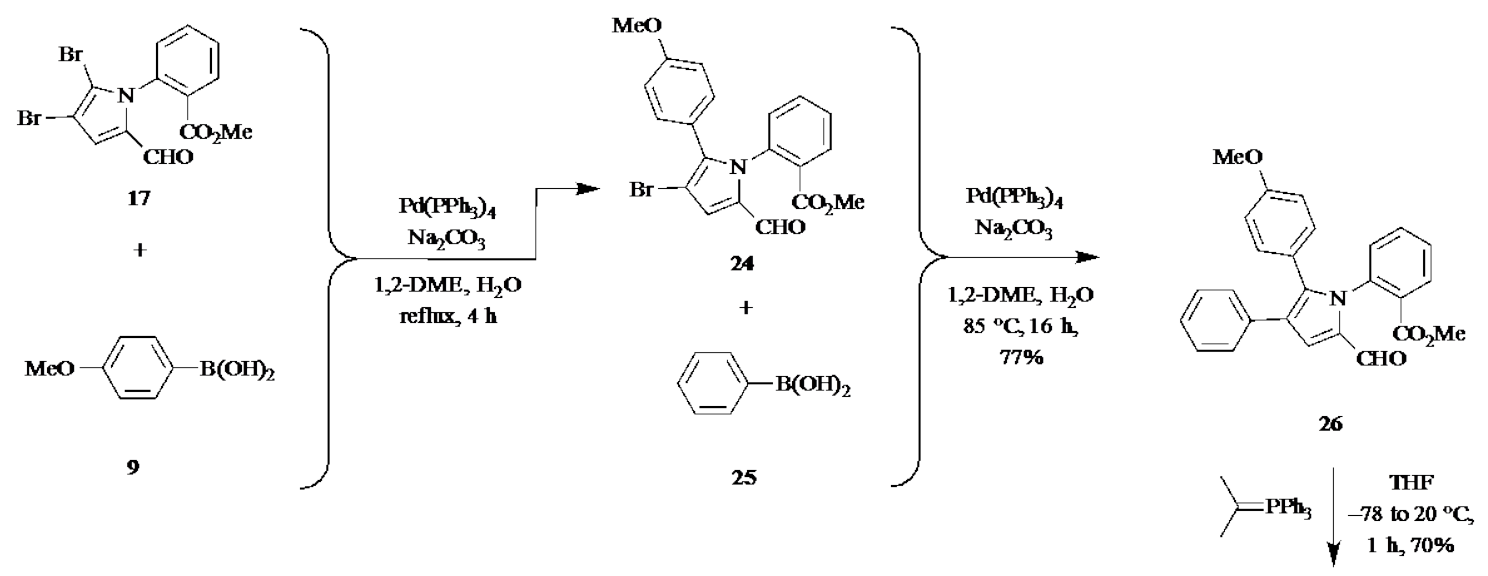

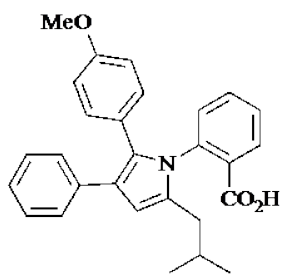

29

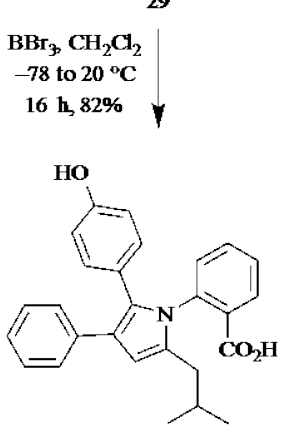

30
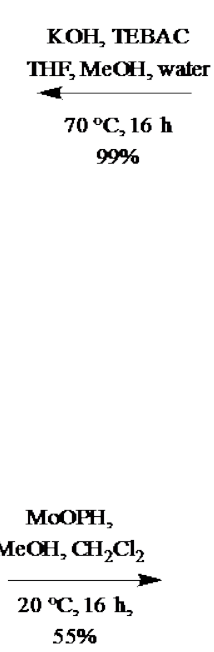

$55 \%$

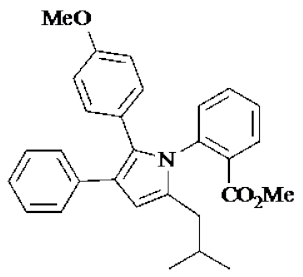

28
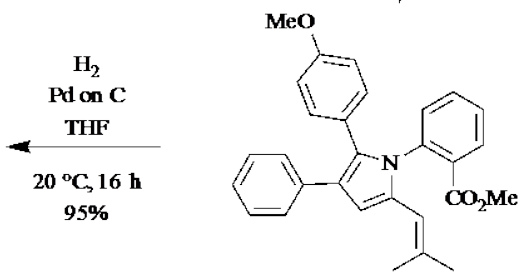

27

Scheme 4: Regioselective diarylation of dibromopyrrole 17 and completion of a synthesis of discoipyrrole B (2)

The acquisition of the differentially triarylated pyrrole 26 allowed for the completion of a total synthesis of discoipyrrole B (2) using the same protocols as described above for the assembly of congener A (1). Specifically then, compound 26 was converted into olefin 27 (70\%) using the same ylid as employed previously and the double bond associated with the latter hydrogenated under conventional conditions and thus affording the iso-butyl substituted pyrrole 28 in 95\% yield. Saponification of the last compound then gave, after acidic work-up, benzoic acid 29 (99\%), the structure of which was confirmed by single-crystal X-ray analysis. When treated with boron tribromide aryl methyl ether 29 was cleaved to give the phenol 30 (82\%) that upon reaction with MoOPH in dichloromethane afforded lactone 2 in $55 \%$ yield. The structure of compound 2 was confirmed by single-crystal $X$-ray analysis. Furthermore, the derived NMR and IR spectral data were in excellent agreement with those reported for discoipyrrole B. 


\section{ASSOCIATED CONTENT}

\section{Supporting Information}

Experimental procedures, spectroscopic and analytical data, NMR spectra of new compounds, and X-ray data for compounds 2, 20, 21 and 29. The Supporting Information is available free of charge on the ACS Publications website at DOI: 10. 10-21/acs. orglett. XXXXXX.

\section{AUTHOR INFORMATION}

\section{Corresponding Author}

*E-mai1: Martin. Banwe11@anu. edu. au.

\section{Notes}

The authors declare no competing financial interest.

\section{ACKNOWLEDGEMENTS}

We thank the Australian Research Council and the Institute of Advanced Studies for financial support. YZ gratefully acknowledges the China Scholarship Council for support.

\section{REFERENCES}

1. Hu, Y. ; Potts, M. B. ; Coloimo, D. ; Herrera-Herrera, M. L. ; Legako, A. G. ; Yousufuddin, M. ; White, M. A. ; MacMillan, J. B. J. Am. Chem. Soc., 2013, 135, 13387.

2. Potts, M. B. ; Kim, H. S. ; Fisher, K. W. ; Hu, Y. ; Carrasco, Y. P. ; Bulut, G. B. ; Ou, Y-H. ; Herrera-Herrera, M. L. ; Cubillos, F. ; Mendiratta, S. ; Xiao, G. ; Ofree, M. ; Ideker, T. ; Xie, Y. ; Huang, L. J. ; Lewis, R. E. ; MacMillan, J. B. ; White, M. A. Sci. Signaling, 2013, 6 (297), ra90.

3. (a) Ford, C. E. ; Lau, S. K. ; Zhu, C. Q. ; Andersson, T. ; Tsao, M. S. ; Voge1, W. F. Br. J. Cancer, 2007, 96, 808; (b) Zhang, K. ; Corsa, C. A. ; Ponik, S. M. ; Prior, J. L. ; Piwnica-Worms, D. ; Eliceiri, K. W. ; Keely, P. J. ; Longmore, G. D. Nature Cell Biol., 2013, 15, 677; (c) Poude1, B. ; Lee, Y-M. ; Kim, D-K. Acta Biochim. Biophys. Sin., doi:10. 1093/abbs/gmv005.

4. (a) Vogel, W. ; Gish, G. D. ; Alves, F. ; Pawson, T. Mol. Cell., 1997, 1, 13; (b) Shrivastava, A. ; Radziejewski, C. ; Campbe11, E. ; Kovac, L. ; McGlynn, M. T. ; Ryan, E. Mol. Cell, 1997, 1, 25.

5. Xu, L. ; Servais, J. ; Polur, I. ; Kim, D. ; Lee, P. L. ; Chung, K. ; Li, Y. Arth. Rheum., 2010, 62, 2736.

6. Shih, J-L. ; Nguyen, T. S. ; May, J. A. Angew. Chem. Int. Ed., 2015, 54, 9931. 
7. A synthesis of some related systems has been reported recently: Koca, I. ; Saçmaci, M. ; Yilmaz, F. ; Üngören, S. H. J. Heterocyclic Chem., 2014, 51, 212.

8. (a) Handy, S. T. ; Sabatini, J. J. Org. Lett., 2006, 8, 1537 ;

(b) Ando, N. ; Terashima, S. Tetrahedron, 2010, 66, 6224.

9. For reviews on the palladium-catalyzed cross coupling reactions of halogenated pyrroles see (a) Banwe11, M. G. ; Goodwin, T. E. ; Ng, S. ; Smith, J. A. ; Wong, D. A. Eur. J. Org. Chem., 2006, 3043; (b) Rossi, R. ; Bellina, F. ; Lessi, M. Adv. Synth. Catal., 2012, 354, 1181.

10. For related conversions see Wang, D-S. ; Ye, Z-S. ; Chen, Q-A. ; Zhou, Y-G. ; Yu, C-B. ; Fan, H-J. ; Duan, Y. J. Am. Chem. Soc., 2011, 133, 8866.

11. See, for example, (a) Antilla, J. C. ; Baskin, J. M. ; Barder, T. E. ; Buchwald, S. L. J. Org. Chem., 2004, 69, 5578; (b) Altmann, R. A. ; Buchwald, S. L. ; Nature Protocols, 2007, 2, 2474; (b) Ma, H-C. ; Jiang, X-Z. J. Org. Chem., 2007, 72, 8943. For a useful review on modern variants of the Ullmann and Goldberg reactions see (d) Kunz, K. ; Scholz, U. ; Ganzer, D. Synlett., 2003, 2428.

12. Hwang, S. J. ; Cho, S. H. ; Chang, S. J. Am. Chem. Soc., 2008, 130, 16158.

13. Mokrov, G. V. ; Likhosherstov, A. M. ; Gewald, R. ; Schindler, R. Heterocycles, 2008, 75, 2713.

14. (a) Chien, C-S. ; Takanami, T. ; Kawasaki, T. ; Sakamoto, M. Chem. Pharm. Bull., 1985, 33, 1843; (b) Chien, C-S. ; Hasegawa, A. ; Kawasaki, T. ; Sakamoto, M. Chem. Pharm. Bu11., 1986, 34, 1493; (c) Kawasaki, T. ; Nonaka, Y. ; Matsumura, K. ; Monai, M. ; Sakamoto, M. Synth. Commun., 1999, 29, 3251; (d) Altinis Kiraz, C. I. ; Emge, T. J. ; Jimenez, L. S. J. Org. Chem., 2004, 69, 2200; (e) Karadeolian, A. ; Kerr, M. A. J. Org. Chem., 2010, 75, 6830 .

15. Vedejs, E. ; Larsen, S. Org. Synth., 1985, 64, 127.

16. For related examples of the regioselective arylation of polyhalogenated pyrroles see: (a) Banwe11, M. G. ; Flynn, B. L. ; Hame1, E. ; Hockless, D. C. R. Chem. Commun., 1997, 207; (b) Zhang, Y. ; Handy, S. T. Open Org. Chem. J., 2008, 2, 58. 